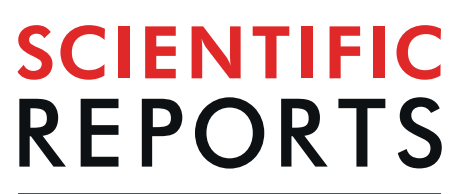

natureresearch

\title{
OPEN Inactivated alpha toxin from Clostridium novyi type B in nano- emulsion protect partially protects Swiss mice from lethal alpha toxin challenge
}

\author{
Mellanie Karoline C. Felix ${ }^{1}$, Tullio T. Deusdará ${ }^{1}$, Lucas Samuel S. Santos ${ }^{1}$, \\ Raimundo Wagner S. Aguiar ${ }^{1}$, Roberto Franco T. Corrêa ${ }^{1}$, Igor V. Brandi ${ }^{2}$, Eliane M. Sobrinho ${ }^{3}$, \\ Bergmann M. Ribeiro $\mathbb{D}^{4}$, Luis André M. Mariúba ${ }^{5}$, Paulo A. Nogueira ${ }^{5}$, Kattyanne S. Costa \\ Kelvinson F. Viana ${ }^{7}$ \& Alex Sander R. Cangussu $\mathbb{D}^{1}$
}

Nano-emulsions are promising carriers for antigen delivery. Here, we evaluated the efficacy of a wateroil nano-emulsion containing concentrated, inactivated Clostridium novyi (C. novyi) type B supernatant culture (nano-iCnB) in protecting Swiss mice against a lethal dose of alpha toxin concentrated extract. Proteins were confirmed in the nano-iCnB and their stabilities were determined according physical parameters such as Zeta Potential (ZP). Biochemical, hematological parameters and morphological appearance of liver, spleen and thigh muscle alterations were examined to determine the safety of the compound. Partial protection against lethal doses was achieved in immunized mice despite low IgG titers. These data suggest that our nano-emulsion is a simple and efficient method of promoting antigen delivery for toxin-related diseases.

C. novyi type B is a strict anaerobic, endospore-forming, gram-positive bacterium. Its major virulence factor is an alpha toxin that causes necrotic hepatitis, known as black disease. Black disease symptoms include hemoglobinuria, reduced appetite, fever, lethargy, decreased milk production and blood-stained feces, all of which reduce productivity in sheep, horses, pigs and cattle ${ }^{1,2}$. Pathogenesis begins with spore germination in the liver, followed by development of vegetative cells and production of alpha toxin. Liver infection causes necrotic infarction with thick areas of hyperemia ${ }^{1,3,4}$. The acute disease is rapidly progressive and associated with a high mortality rate ra $^{5,6}$

Current vaccines are composed of multiple antigens adsorbed on aluminum hydroxide; nevertheless, their efficacies remain unsatisfying ${ }^{4,7,8}$. Aqueous adjuvant induces short-term responses, besides the fact that costs with handling and revaccination make them more expensive $e^{9,10}$. Thus, alternatives to reduce animal handling as well as elimination of interactions between antigens are necessary for vaccine development ${ }^{10}$. Antigens in nano-emulsions are promising alternatives to improve vaccine efficacy because they delay antigen delivery, generating good cellular and humoral responses for long periods ${ }^{10,11}$. Here, we demonstrated that our formulation is a substantial improvement and advance in terms of adsorption of antigens for control of clostridiosis.

\footnotetext{
${ }^{1}$ Federal University of Tocantins - Postgraduate program in Biotechnology, Gurupi, TO, Brazil. ${ }^{2}$ Institute of Agrarian Science, Federal University of Minas Gerais, Montes Claros, MG, Brazil. ${ }^{3}$ Federal Institute of North Minas Gerais, Araçuaí, MG, Brazil. ${ }^{4}$ University of Brasília, Institute of Biological Sciences, Brasília, DF, Brazil. ${ }^{5}$ Institute Leônidas

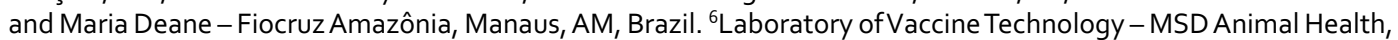
Montes Claros, MG, Brazil. ${ }^{7}$ Federal Integrated University of Latin Americana - Laboratory of Molecular Biology and Biochemistry-ICVN, Foz do Iguaçu, PR, Brazil. Correspondence and requests for materials should be addressed to A.S.R.C. (email: alexcangussu@uft.edu.br)
} 

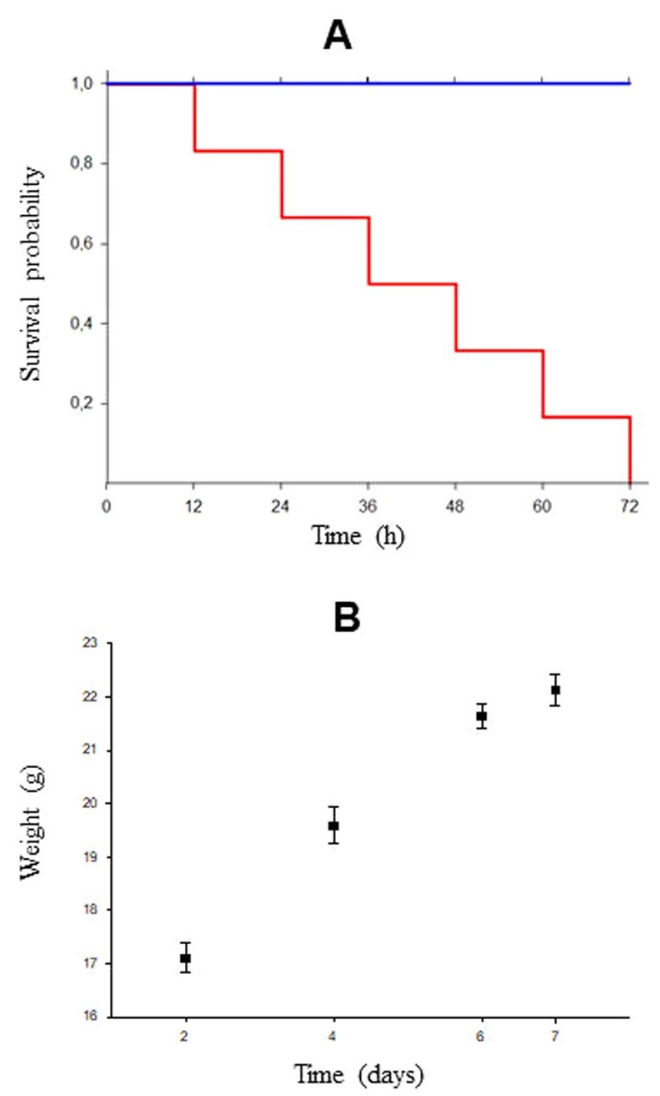

- Weight gain $(\mathrm{g})$ _ active alpha toxin _ inactivated alpha toxin

Figure 1. Determination of the lethal dose $\left(\mathrm{LD}_{50} / \mathrm{mL}\right)$ and inactivation process. (A) Survival probability of Swiss mice inoculated with active and inactivated alpha toxin. (B) Weight gain of Swiss mice inoculated with inactivated alpha toxin.

\section{Results}

Physical characteristics analysis of the nano-iCnB. Alpha toxin-producing C. novyi cause gas gangrene, characterized by hemorrhage and muscle and soft tissue. After alpha toxin production, mice were inoculated to determine the lethal dose $\left(\mathrm{LD}_{50} / \mathrm{mL}\right)$ up to 72 hours (Fig. $\left.1 \mathrm{~A}\right)$. The inactivation process was confirmed by administration of inactivated alpha toxin for 7 days, noting absence of clinical signs and monitoring weight gain (Fig. 1B). The nano-iCnB was formulated in the $40 \%$ aqueous phase in a Vivaspin 6 MWCO 30000 at a final antigen concentration of $0.16 \mathrm{mg} / \mathrm{ml}$, and $60 \%$ oil phase with ISA adjuvant. To assess stability of nano-iCnB from an ultrafiltrate of inactivated antigen, we compared the Zeta Potential (ZP) with antigen-free emulsion (nanomilliQW) consisting of $40 / 60 \%$ aqueous-oil phase (ISA adjuvant). The nano-milliQW had differentiated peaks with droplets of three diameters: $896.5,618.5$ and $1280 \mathrm{~nm}$, suggesting that the system containing only adjuvant did not generate adequate size control. The intensity of $896.5 \mathrm{~nm}$ corresponded to $41 \%$ of the sample. The nano$\mathrm{iCnB}$ revealed symmetrical peaks around of 509.4 and $882.4 \mathrm{~nm}$, corresponding to $33.3 \%$ and $66.7 \%$ of the sample, respectively, confirming that proteins from nano-iCnB containing various sizes were adsorbed in nano-iCnB emulsion (Fig. 2A,B).

Stability of the emulsion can be expressed according to ZP value, with higher ZP indicating lower stability on account of repulsive forces between charged particles that repel each other, overcoming the natural tendency of aggregation. The zeta potential of nano-iCnB was $-0.657 \mathrm{mV}$, lower than nano-milliQW value of $-0.896 \mathrm{mV}$, confirming its stability (Fig. 3A,B).

Immunogenicity and efficacy test of the nano-iCnB. Alpha toxin is a $250 \mathrm{kDa}$ protein secreted in culture supernatants. We confirmed this using SDS/PAGE (Fig. 4A) and immunoblotting (Fig. 4B). Nano-iCnB's ability to deliver antigen was demonstrated by detection of IgG in immunized swiss mice. Pooled sera of immunized animals reacted with the major antigen in the culture supernatants (Fig. 4B). We also determined antibody levels with reactivity of nano-iCnB individually. Individual mouse serum confirmed major reactivity with nano-iCnB antigen when compared with individual mouse serum of nano-milliQW or non-immunized mice (Fig. 4C). Pooled sera and individual mouse serum reacted specifically with the $250 \mathrm{kDa}$ alpha toxin adsorbed in nano-iCnB indicating our nano-emulsion promoted antigen delivery (Fig. 4B,C). 
A
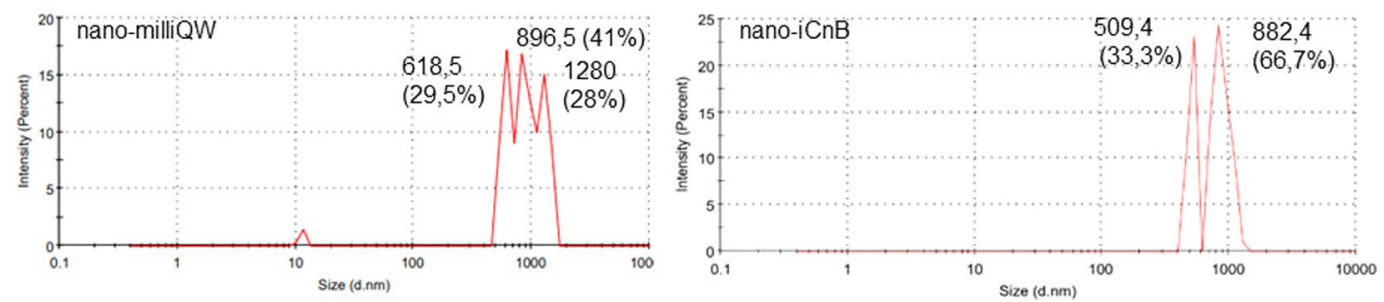

B
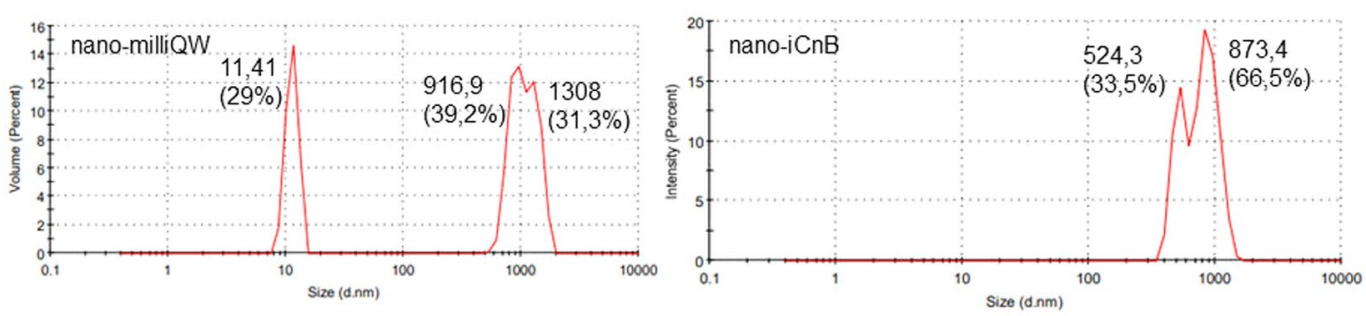

Figure 2. Physical characteristics of nano-iCnB and nano-milliQW nano-emulsion by Zetasizer Nano ZS90 Malvern Instruments. (A) Protein encapsulated droplets intensity. (B) Protein encapsulated droplet volume.

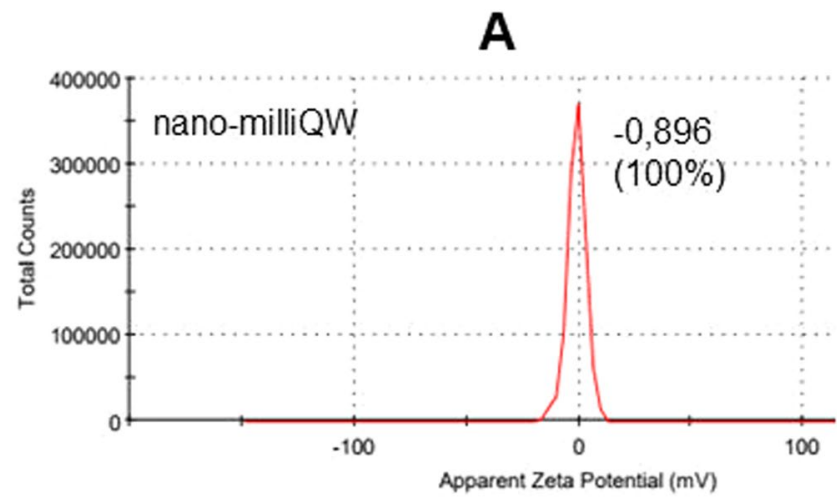

B

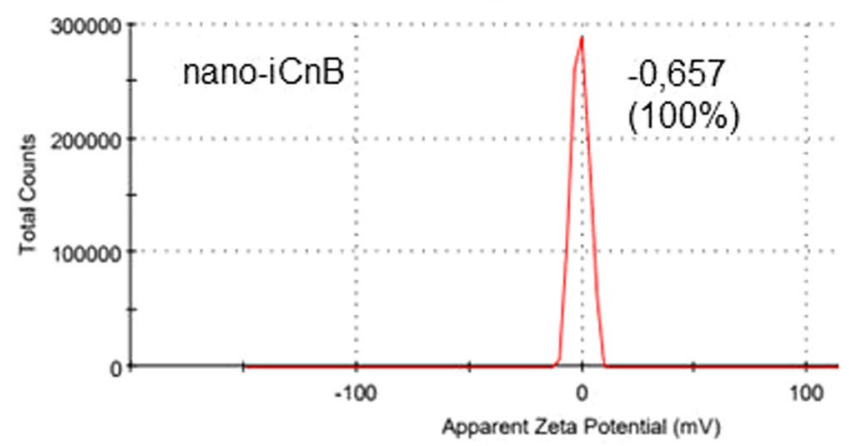

Figure 3. Physical characteristics of nano-iCnB and nano-milliQW nano-emulsion using Zetasizer Nano ZS90 Malvern Instruments. (A) Zeta Potential of nano-milliQW. (B) Zeta Potential of nano-iCnB.

Safety of nano-iCnB according to liver function test and hematological data. The safety of nano-iCnB was demonstrated by absence of edema in the right thigh where the injection was performed (Fig. 5A). The spleens of nano-iCnB-immunized mice showed increased weight (Fig. 5B). Analysis of the variation of liver weight in these animals showed significant differences between the experimental groups. However, the nano-iCnB, nano-milliQW mice or non-immunized-challenged did not cause edema at the injection site (Fig. 5C). The blood samples collected from mice challenged with alpha toxin-concentrated extract before 


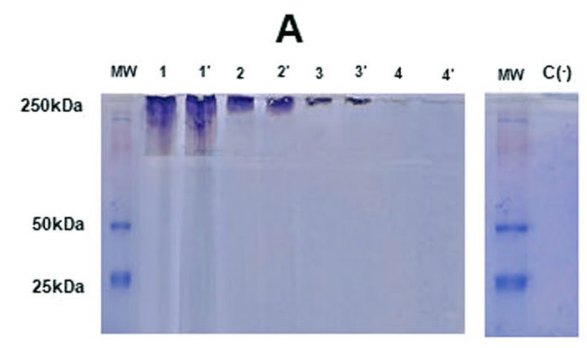

B

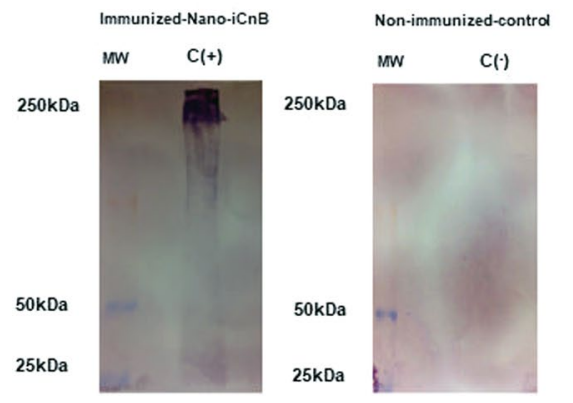

C

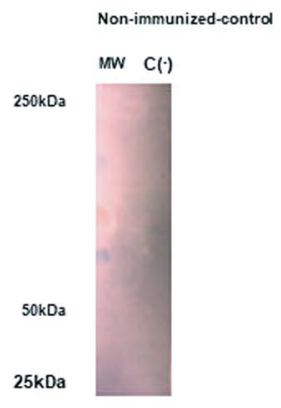

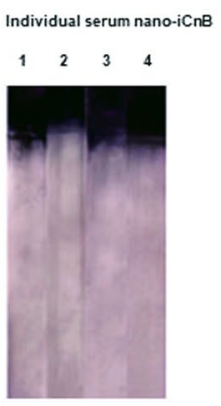

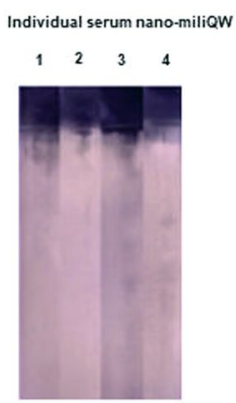

Figure 4. Antigenicity, immunogenicity and efficacy of nano-iCnB evaluated in Swiss mice. (A) Inactivated alpha toxin $(>250 \mathrm{kDa})$ on $11 \%$ SDS-polyacrylamide gel electrophoresis. MW - Molecular weight. Line $1,1^{\prime} ; 2$, $2^{\prime} ; 3,3^{\prime} ; 4,4^{\prime}$, are representing dilution of inactivated alpha toxin: pure, $1: 2 ; 1: 4$ and 1:8 in duplicate; respectively. (B) Immunoblotting of immunized group (nano-iCnB). (C) Immunoblotting of individual mice serum immunized with nano-iCnB and nano-milliQW.

euthanasia were used to evaluate changes in hematological parameters and liver function (Table 1). These showed clinical pictures of leukocytosis, polycythemia, increased levels of alanine transaminase (AST), alanine transaminase (ALT) and alkaline phosphatase (AP) of non-immunized-challenged mice. Nano-iCnB immunized, Nano-milliQW or non-immunized-control mice showed normal values in all parameters and normal levels of AST, ALT and AP, while non immunized-challenged showed anemia.

Partial protection of nano-iCnB. Kaplan-Meier survival curves showed that mice immunized with nano-iCnB had greater survival when challenged with a lethal dose of $157 \mathrm{LD}_{50} \cdot \mathrm{g}^{-1}$ than non-immunized-challenged or nano-milliQW mice (Fig. 6). The lethal dose generated symptoms in non-immunized-challenged and nano-milliQW mice, characterized by shaggy hairs, brown shading, rapid breathing, lacrimation, abdominal swelling and lethargy. Deaths started after 12 hours of the administration of challenge dose corresponding to 157 $\mathrm{LD}_{50} \cdot \mathrm{g}^{-1}$ of alpha toxin. The $\mathrm{LT}_{50}$ of the non-immunized-challenged group of 20.0 (15.1-24.9), while the LT50s of nano-milliQW and nano-iCnB were 30.0 (19.9-40.1) and 56.0 (40.8-71.2), respectively. The log rank statistic for the survival curves showed a significant difference between survival curves $(\mathrm{p}=0.002)$. The survival curves were compared to the curves of the three groups (nano-milliQW, non-immunized-challenged and nano-iCnB) simultaneously, using TL50 as the comparison unit. Only animals in the nano iCnB group showed significant differences.

\section{Discussion}

Alpha toxin-producing C. novyi type B has substantial economic importance because of the damage it generates in livestock production chains. Here, we evaluated a nano-iCnB containing alpha toxin with 2178 amino acid residues, molecular weight ranging from 260 to $280 \mathrm{kDa}^{12,13}$. We demonstrated partial protection in immunized Swiss mice using nano-iCnB, indicating its promising action as carriers for antigen delivery.

Critical reports regarding the use of aluminum hydroxide adjuvant for clostridial vaccines suggested that both size and conformational changes of toxoid affect surface-protein interactions with aluminum ligands during administration, thereby affecting the immune response ${ }^{14}$. New controlled release systems have been proposed as antigen delivery vehicles because of their utility as immunological adjuvants, with absence of toxicity, biodegradability, and slow release of encapsulated antigens ${ }^{14}$. Here, we observed that the nano-iCnB showed a high volume with $66.5 \%$ of the sample, suggesting improved encapsulation and controlled release of antigen (Fig. 2B).

The present study represents an innovative and simple technological strategy for the emulsification of inactivated toxins as immunogen ${ }^{9,10}$. Polymers have been used in bovine vaccine such as herpesvirus 1 (BHV-1), infectious bovine rhinotracheitis (IBR), and inactivated C. botulinum toxin with protection and safety being similar to that of the conventional vaccine ${ }^{15-17}$. As a proof of concept in this murine model, we consider it to be a relevant technological contribution of the use of nano-iCnB for immunization of Swiss mice. It represents an improvement in production of multiple antigens vaccines, specifically for the use of alpha toxin of $C$. novyi for control of hepatic necrosis.

Size, intensity and ZP are parameters used for analysis of interactions, transport of molecules and the availability of antigen at the immunization site ${ }^{18}$. Here, the nano-milliQW consisted of droplets of three diameters: 
A

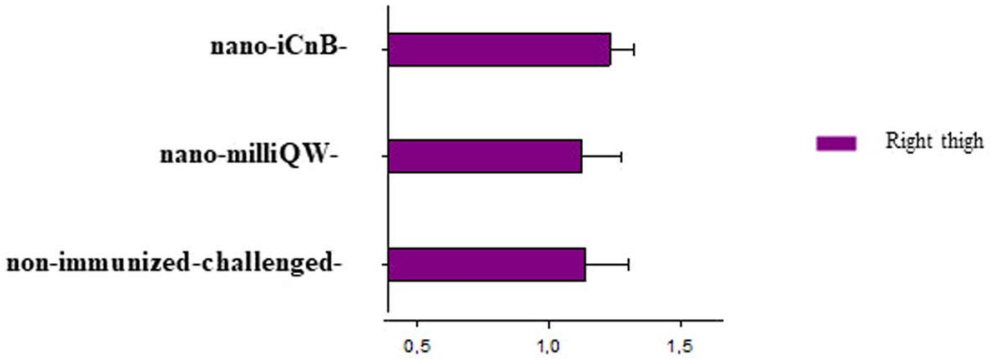

B

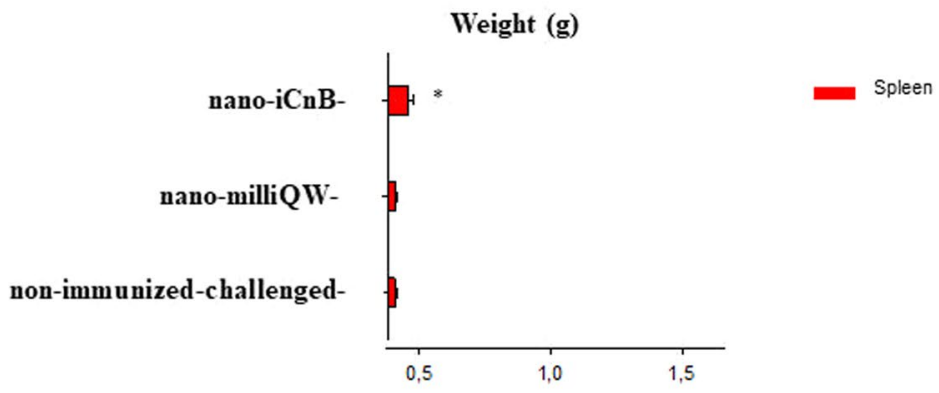

C

Weight (g)

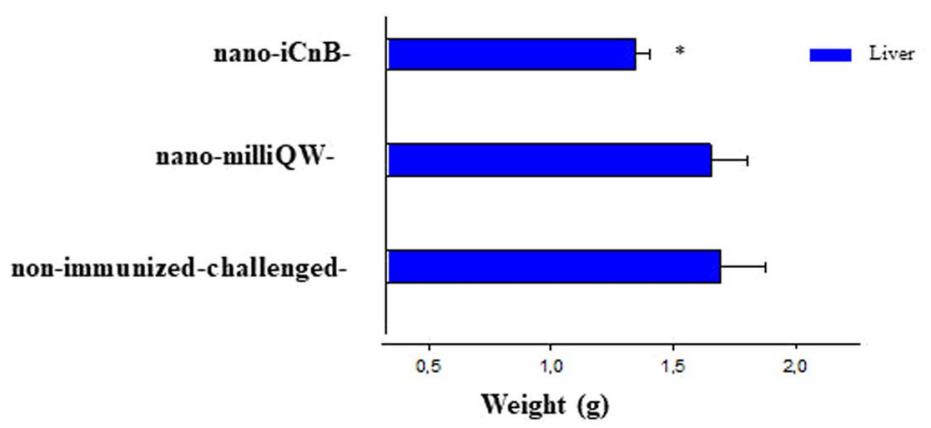

Figure 5. Safety test of immunized mice with nano-iCnB. (A) Morphological appearance of right thigh inoculated. (B,C) Spleen and liver of immunized and non-immunized-challenged mice as well as the nanoemulsion group. ${ }^{*} \mathrm{p}<0.05$ statistic differences.

\begin{tabular}{|l|l|l|c|c|c|}
\hline Parameters & Nano-milliQW & $\begin{array}{l}\text { Non-immunized- } \\
\text { control }\end{array}$ & Nano-iCnB & $\begin{array}{l}\text { Non-immunized- } \\
\text { challenged }\end{array}$ & Reference \\
\hline Total Leukocytes, $\left(\mathrm{mm}^{3}\right)$ & $9600(864)^{\mathrm{ns}}$ & $8466(982)$ & $11733(499)$ & $12933(7128)$ & $4300-10000,\left(\mathrm{~mm}^{3}\right)$ \\
\hline Hemoglobin, $(\mathrm{g} / \mathrm{dL})$ & $14,73(0,51)^{\mathrm{ns}}$ & $10,60(2,80)$ & $16,17(0,51)$ & $20,73(1,80)^{*}$ & $13-17,(\mathrm{~g} / \mathrm{dL})$ \\
\hline Hematocrit, $(\%)$ & $44,33(1,53)^{\mathrm{ns}}$ & $38,80(4,50)$ & $48,67(1,53)$ & $64,67(3,05)^{*}$ & $39-51,(\%)$ \\
\hline Alanine Transaminase (ALT), (U/L) & $38(12)^{\mathrm{ns}}$ & $32(12)$ & $31(11)$ & $211(73)^{*}$ & $26-60,(\mathrm{U} / \mathrm{L})$ \\
\hline Aspartate aminotransferase (AST), (U/L) & $130(65)^{\mathrm{ns}}$ & $156(38)$ & $180(49)$ & $414(72)^{*}$ & $81-184,(\mathrm{U} / \mathrm{L})$ \\
\hline Alkaline phosphatase (AP), (U/L) & $125(74)^{\mathrm{ns}}$ & $183(7,20)$ & $190(6)$ & $206(28)$ & $63-196,(\mathrm{U} / \mathrm{L})$ \\
\hline
\end{tabular}

Table 1. Hematologic data and liver function test of Swiss mice immunized with nano-iCnB. Non-immunizedcontrol (healthy animals); nano-milliQW; nano-iCnB; Non-Immunized-challenged with $157 \mathrm{LD}_{50} \cdot \mathrm{g}^{-1}$. ns - not significant - sera from Swiss mice non-immunized-control vs sera from Swiss mice inoculated with nanomilliQW. *significant - hemoglobin $(\mathrm{p}<0.05)$; hematocrit $(\mathrm{p}<0.05)$; ALT $(\mathrm{p}<0.04)$; AST $(\mathrm{p}<0.01)$ sera from immunized Swiss mice vs Non-immunized-challenged.

$896.5,618.5$ and $1280 \mathrm{~nm}$, suggesting that the system containing only the adjuvant did not produce adequate size control. However, the nano-iCnB showed only two bands: 509.4 and $882.4 \mathrm{~nm}$ with high volume, suggesting that the antigen helps to control droplet size in the nano-emulsion, giving rise to a fine emulsion ${ }^{19,20}$. The surface area to the volume in nanoemulsion can be affected by properties of the particles and their interaction with other systems. Small size particles show higher barrier properties for evaporation and increase the occlusion. These data suggest that the effect is affected by applied volume, particle size and crystallinity ${ }^{21}$.

$\mathrm{ZP}$ values are directly related to the stability of products, being obtained by the ratio of repulsion forces between charged particles that avoids the natural tendency to aggregate ${ }^{22}$. In nano-iCnB, the ZP was lower than 


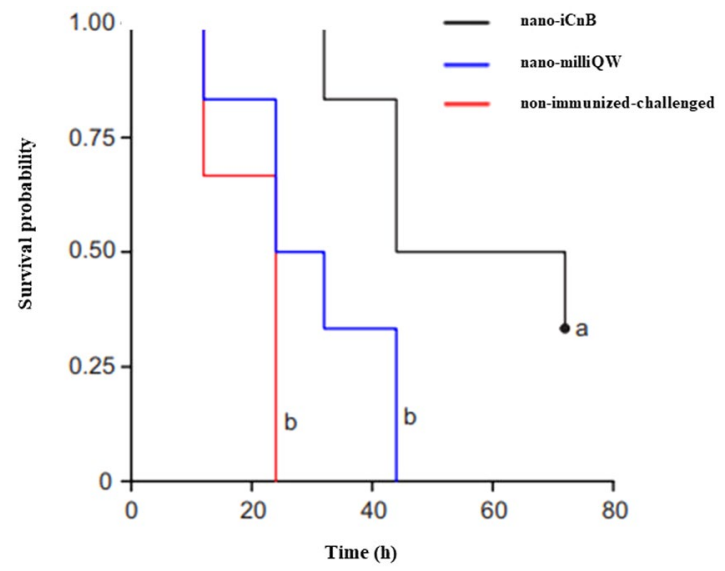

Figure 6. Survival curves of Swiss mice of experimental groups using the Kaplan-Meier method. The LT50 of the non-immunized-challenged group of 20.0 (15.1-24.9), while the LT50s of nano-milliQW and nano-iCnB were 30.0 (19.9-40.1) and 56.0 (40.8-71.2), respectively. The log rank statistic for the survival curves showed a significant difference between survival curves $(\mathrm{p}=0.002)$. The survival curves were compared to the curves of the three groups (nano-milliQW, non-immunized-challenged and nano-iCnB) simultaneously, using TL50 as the comparison unit. Only animals in the nano $\mathrm{iCnB}$ group showed significant differences.

that of nano-milliQW, demonstrating desirable physical characteristics for a W/O type emulsion vaccine formulation $^{20}$. This suggests product stability, controlled release and stimulation of the immune response ${ }^{18,23}$.

Montanide ISA 61 VG is a new ready-to-use mineral oil-based adjuvant developed by SEPPIC Inc. (SEPPIC, France) being employed in the improvement of vaccines against FMD and BVDV virus ${ }^{10,14}$. Significant reduction of viremia (BVDV), even with a lower viral antigen concentration, was observed with use of vaccines formulated with ISA 61 VG. Here, for the first time, we used Montanide ISA 61 VG adjuvant together with bacterial antigen in nanoemulsion, and detected partial protection of Swiss mice after dose challenge $\left(150 \mathrm{LD}_{50} \mathrm{~g}^{-1}\right)$ with alpha toxin from $C$ novyi tipe B. Immunized animals had later manifestations of the disease in some individuals, with a survival rate of $40 \%$. Hepatocellular lesions and hepatocyte permeability may be indicated by changes in AST, ALT and cholestatic disorders caused by obstruction of the bile ducts, suggesting high metabolic activity in serum, as occurs in necrosis or disease in target tissues ${ }^{24,25}$. In contrast, nano-iCnB mice showed normal biochemical and hematological parameters. Furthermore, these animals did show signals of hypertrophy and congestion in liver. No edema in the right thigh nor with body or liver weight after 7 days of the final immunization indicated its safety. These data suggest that our nano-emulsion is a simple and efficient method that can be used to promote antigen delivery for toxin-related diseases.

This study had technical limitations as to improve the concentration of antigen present in nanoemulsion, as well to explore nano emulsion containing multiples antigen clostridial understanding your protective effect.

In conclusion, we proposed a simple and straightforward method of determining the effect of inactivated alpha toxin from C. novyi type B on a nanoemulsion. Nano-iCnB displayed safe and effective for stimulating immune responses in Swiss mice challenged with lethal doses of toxin.

\section{Materials and Methods}

Mouse lines and ethics in animal experimentation. Female Swiss mice (Mus musculus) weighing between 17 and $23 \mathrm{~g}$ were purchased from the Goiânia Central Goat Hospital - GO of the Federal University of Goiás (UFG). The animals were kept under conditions controlled for temperature, luminosity and odor. They were given feed (Biobase ${ }^{\circledR}$ - Brazil) and purified water ad libitum. The animals were maintained for a quarantine period of 7 days before the start of the experiments. The study was authorized by the Ethics and Research Committee of the Federal University of Tocantins (UFT) under number 23.101.006.832/2017-53 according to international recommendations for ethics in animal experimentation and by guidelines for animal use and care were based on the standards established by The Brazilian College of Animal Experimentation (COBEA).

Anesthesia and euthanasia. Blood collection and morphological analyses of liver, spleen and inoculated right thighs were based on three animals per group at 0,21 and 42 days. Prior to sample collection, the animals were anesthetized with ketamine $300 \mathrm{mg} / \mathrm{Kg}$ (Vetbrands, Brasil) and xylazine $22 \mathrm{mg} / \mathrm{Kg}$ (Vallée S/A) intraperitoneally and were euthanized by cervical dislocation to achieve rapid and painless death when mice showed intense lethargy, according to ethical protocols ${ }^{26}$. Immediately, cardiac puncture was performed and organs were collected before euthanasia at each time point for hematological and liver function tests, organ morphology and immunogenicity assays. During the challenge stage with active alpha toxin, animals in the experimental groups were anesthetized with ketamine and xylazine at the same concentration at the onset of clinical signs of infection.

Bacterial lineage and culture conditions. C. novyi type B, virulent strain used for alpha toxin production and vaccinal antigen purchased from the NCTC (NCTC - National Collection Type cultures) was grown and stored in a culture bank with storage at the Laboratory of Biomolecules and Vaccines of the Federal University 
of Tocantins (LaBVac/UFT). Alpha toxin production was started in culture of C. novyi type B in Tarozzi culture medium and incubated at $37 \pm 2^{\circ} \mathrm{C}$ in BOD for 24 hours. Cultures were spun at $3000 \mathrm{~g}$ for 15 minutes to collect the supernatants. Vivaspin $6 \mathrm{MWCO} 30000$ membranes were used to concentrate inactivated alpha toxin used in W/O 40/60 nano-emulsions.

Determination of lethal dose and the inactivation process of alpha toxin in mice. Toxicity of alpha toxin C. novyi type B was determined in Swiss mice by diluting the toxin from 1:4-1:16. From each dilution, $200 \mu \mathrm{L}$ was administered intraperitoneally to four mice ${ }^{27}$. Determination of lethal dose $\left(\mathrm{LD}_{50} / \mathrm{mL}\right)$ was performed by observing the effect of the alpha toxin in the inoculated animals for 72 hours and quantifying by mathematical interpolation ${ }^{28}$. A lethal dose of $157 \mathrm{DL}_{50} \cdot \mathrm{g}^{-1}$ was employed for challenge test (Fig. 1A).

Inactivation of alpha toxin in formaldehyde was performed at a ratio of $0.6 \% \mathrm{v} / \mathrm{v}$ at $37^{\circ} \mathrm{C}$ under gentle agitation for 7 days. The inactivation test was performed with $200 \mu$ intraperitoneal administration in three animals, followed by observation of the animals for 7 days $^{29}$. Samples were considered inactivated if $100 \%$ of animals survived (Fig. 1B). An antigenic concentration of $0.16 \mathrm{mg} / \mathrm{ml}^{-g^{-1}}$ was employed for the vaccine dose.

W/O 40/60 nanoemulsion. In addition to $\mathrm{LD}_{50} / \mathrm{mL}$, the total protein concentration of the antigen sample was determined using a Lab test ${ }^{\circledR}$ - total proteins 99-250 kit. Inactivated alpha toxin was emulsified in ISA adjuvant (MONTANIDE ${ }^{\mathrm{TM}}$ ISA $61 \mathrm{VG}$, Seppic, Brazil) to a final concentration of $0.16 \mathrm{mg} / \mathrm{ml}$ in the $40 \%$ aqueous phase and the $60 \%$ ISA adjuvant (oily phase). Nano-iCnB and nano-milliQW were prepared by passing the volume between sterile syringes connected by a silicone hose.

Physical characteristics of the nano-iCnB. The physical characteristics of nano-iCnB were evaluated in the presence (culture supernatant) and water (nano-milliQW) of inactivated alpha toxin22. The diameter measurements of the emulsion droplets and zeta potential were performed using a Zetasizer Nano ZS90 from Malvern Instruments at $25^{\circ} \mathrm{C}$. Samples were diluted using ISA adjuvant at a ratio of 1:10.

The Dynamic Light Scattering (DLS) technique was used to determine the diameter of the droplets. In this technique, a beam of light is focused on the sample and droplet size is estimated from fluctuations in the intensity of light scattered at a given angle. The zeta potential is a measure of the magnitude of the static charges present at the interface between the droplets and the solvent. This parameter is important because it affects the stability of the droplets.

Characterization of immunogenicity of nano-iCnB in swiss mice by immunoblotting. Characterization of the inactivated alpha toxin was performed using SDS/PAGE and antigenicity was evaluated by immunoblotting. We used 11\% SDS/PAGE gels with buffer containing $1.5 \mathrm{M}$ Tris- $\mathrm{HCl} \mathrm{pH} 8.8$ and $0.4 \%$ SDS. Electrophoresis buffer contained $25 \mathrm{mM}$ Tris- $\mathrm{HCl} \mathrm{pH} \mathrm{8.3,200} \mathrm{mM} \mathrm{glycine} \mathrm{and} 1 \%$ SDS. The samples were heated to $100^{\circ} \mathrm{C}$ for 5 minutes and were run at 70 Volts. The gels were stained with Coomassie blue for $12 \mathrm{~h}$, and the protein bands were transferred to polyvinyl difluoride (PVDF) membranes using Trans-Blot ${ }^{\circledR}$ Turbo ${ }^{\mathrm{TM}}$ Transfer System from Bio-Rad Lab and buffer with $5.82 \mathrm{~g}$ of tris base, $2.83 \mathrm{~g}$ glycine, $3.75 \mathrm{~mL} 10 \%$ SDS and $20 \%$ methanol, pH 9.2 for 60 minutes.

Electrotransfer was performed at 15 volts for 30 minutes. After transfer, the membranes were immersed in blocking solution with 1x PBS buffer $+3 \%$ milk powder, left overnight, and were subsequently washed in PBS $0.05 \%$-Tween three times. Sera from healthy and diseased animals were diluted 1:2000 in 1x PBS $+0.5 \%$ BSA buffer and were applied to the membranes with gentle agitation for 60 minutes. Then, membranes were washed again for addition of alkaline phosphatase-conjugated anti-mouse at a dilution of 1:10000 under gentle agitation for 60 minutes. Membranes were again washed with PBS 0.05\% Tween three times and once with alkaline phosphatase buffer under gentle agitation for 5 minutes. Membranes were submerged in NBT/BCIP substrate and the reaction was subsequently stopped. The membranes were washed with distilled water and dried in an oven.

Experimental design. Female Swiss mice were separated into three groups (non-immunized, nano-emulsion and immunized) with 10 animals per group. In the immunized group, $100 \mu$ lof the nano-iCnB supernatant were administered at 0,21, 42 days intramuscularly injected into the right thigh. Animals in the nano-emulsion and non-immunized groups were given $100 \mu \mathrm{l}$ of PBS and nano-milliQW, respectively. The three experimental groups were monitored daily with weights measured and challenged with $157 \mathrm{LD}_{50} \cdot \mathrm{g}^{-1}$ after 7 days of the final immunization. Sick animals were anesthetized and euthanized and Kaplan-Meier survival curves were determined.

Morphological appearance of liver, spleen and inoculated right thigh. Three animals were evaluated 7 days after the final immunization (day 42) to evaluate changes in liver, spleen and right thigh morphology. The degree of lesions at the site of administration was evaluated in terms of variation of organ weight, swelling, and redness as follows: 0) alterations absent; 1) discrete changes up to 25\%;2) moderate changes greater than $25 \%$, but less than $50 \%$; and 3 ) severe changes greater than $50 \%$.

Hematologic data and liver function tests. Seven days after the final immunization (day 42), experimental groups were challenged with a lethal dose of $157 \mathrm{LD}_{50} \cdot \mathrm{g}^{-1}$, followed by blood collection in the first 24 hours. The biological material was analyzed by the Veterinary Pet Shop Dog Center (Gurupi/TO - Brazil). Aspartate transaminase (AST), alanine transaminase (ALT), alkaline phosphatase (AP), leukograms, hemoglobin and hematocrit were determined. A group of three non-immunized animals were challenged with a lethal dose of $157 \mathrm{LD}_{50} \cdot \mathrm{g}^{-1}$ for the collection of sera from animals infected with active alpha toxin. 
Statistical analysis. The Kruskal-Wallis ANOVA test was used to verify the average and zeta-specific (ZS) sizes of the nano-iCnB and nano-milliQW. Morphological differences in liver, spleen, as well as liver and hematological data were compared between the immunized, nano-emulsion, non-immunized and sick animal groups (positive control) using data from three animals in each group. Significant differences were defined as $\mathrm{p}<0.05$ with $95 \%$ confidence intervals. Kaplan-Meier survival curves were used to display vaccine efficacy.

Ethics approval and consent to participate. All experiments were performed in accordance with the ethical guidelines for experiments with mice, and the protocols were approved by the National Council for Control of Animal Experimentation, Federal University of Tocantins Animal Experimentation Committee (CEUA $\left.n^{\circ} 23101.006 .832 / 2017-53\right)$. The guidelines for animal use and care were based on the standards established by The Brazilian College of Animal Experimentation (COBEA).

\section{References}

1. Ma, M., Boyd, J. T., Trinh, H. T., Coombs, J. W. \& Fermann, G. J. Fatal myocarditis due to Clostridium novyi type B in a previously healthy woman: Case report and literature review. Scand. J. Infect. Dis. 39, 77-80 (2007).

2. Uzal, F. A., Vidal, J. E., McClane, B. A. \& Gurjar, A. A. Clostridium perfringens toxins involved in mammalian veterinary diseases. Open Toxinology J. 3, 24-42 (2010).

3. Uzal, F. A., Paramidani, M., Assis, R., Morris, W. \& Miyakawa, M. F. Outbreak of clostridial myocarditis in calves. Vet. Rec. 152, 134-136 (2003).

4. Lima, C. G. R. D. et al. Padronização de teste de potência in vitro para vacinas que contenham toxoide alfa de Clostridium novyi tipo B. Arq. Inst. Biol. 78, 507-512 (2011).

5. Navarro, M. A. et al. Pathology of Naturally Occurring Bacillary Hemoglobinuria in Cattle. Vet. Pathol. 54, 457-466 (2017).

6. Hussein, A., El-Amir, Y. O., Aamer, A. A. \& Elghaffar, S. K. A. Bacillary hemoglobinuria in dairy cows: clinical, hematological, biochemical, and pathological alterations. Comp Clin Pathol. 22, 6 (2012).

7. Lobato, F. C. F. et al. Avaliação da potência de vacinas contra Clostridium septicum comercializadas no Brasil. Arq. Inst. Biol. 75, 225-228 (2008)

8. Lobato, F. C. F. et al. Clostridioses Dos Animais De Produção. Vet. e Zootec. 20, 29-48 (2013).

9. Park, M. E. et al. Enhanced immune responses of foot-and-mouth disease vaccine using new oil/gel adjuvant mixtures in pigs and goats. Vaccine. 32, 5221-5227 (2014).

10. Khorasani, A., Madadgar, O., Soleimanjahi, H., Keyvanfar, H. \& Mahravani, H. Evaluation of the efficacy of a new oil-based adjuvant ISA 61 VG FMD vaccine as a potential vaccine for cattle. Iran. J. Vet. Res. 17, 8-12 (2016).

11. Petermann, J. et al. Evaluation of three adjuvants with respect to both adverse effects and the efficacy of antibody production to the Bm86 protein. Exp. Appl. Acarol. 1-13 (2017).

12. Pietrzykowski, E., Cox, J., Zachariou, M. \& MacGregor, A. Development of an Enzyme Immunoassay for the Detection of Clostridium novyi Type B Alpha Toxin. Biologicals 19, 293-298 (1991).

13. Hofmann, F., Herrmann, A., Habermann, E. \& von Eichel-Streiber, C. Sequencing and analysis of the gene encoding the alpha-toxin of clostridium novyi proves its homology to toxins a and B of Clostridium difficile. Mol Gen Genet. 247, 670-679 (1995).

14. Jully, V., Mathot, F., Moniotte, N., Préat, V. \& Lemoine, D. J. Mechanisms of Antigen Adsorption Onto an Aluminum-Hydroxide Adjuvant Evaluated by High-Throughput Screening. Pharm Sci. 105, 1829-1836 (2016).

15. Brasil, Instrução normativa 23, In: M.A.P.A. Diário Oficial da União, nº 23 (2002).

16. Gunbeyaz, M., Faraji, A., Ozkul, A., Pural, N. \& Senel, S. Chitosan based delivery systems for mucosal immunization against bovine herpesvirus 1 (BHV1). Eur J Pharm Sci. 41, 531-545 (2010).

17. Sari, R. S. et al. Anti-botulism single-shot vaccine using chitosan for protein encapsulation by simple coacervation. Anaerobe. 42 , 182-187 (2016).

18. Veenstra, K. A. et al. Analysis of adipose tissue immune gene expression after vaccination of rainbow trout with adjuvanted bacterins reveals an association with side effects. Mol. Immunol. 88, 89-98 (2017).

19. Bhattacharjee, S. \& Ghoshal, S. Phase Transfer of Palladized Nanoscale Zerovalent Iron for Environmental Remediation of Trichloroethene. Environ Sci Technol. 50, 8631-8639 (2016).

20. Javadzadeh, Y., Bahari, L. A. Therapeutic Nanostructures for Dermal and Transdermal Drug Delivery. In: Nano-and microscale drug delivery systems: design and fabrication (ed. Grumezescu, A. M.) 1-16 (Elsevier, 2017).

21. Teeranachaideekul, V., Boonme, P., Souto, E. B., Müller, R. H. \& Junyaprasert, V. B. Influence of oil content on physicochemical properties and skin distribution of Nile red-loaded NLC. J. Control. Release 128, 134-141 (2008).

22. Sun, H. W. et al. Induction of systemic and mucosal immunity against methicillin-resistant Staphylococcus aureus infection by a novel nano-emulsion adjuvant vaccine. Int. J. Nanomedicine. 10, 7275-90 (2015).

23. Tehrani, N. K., Mahdavi, M., Maleki, F., Zarrati, S. \& Tabatabaie, F. The role of Montanide ISA 70 as an adjuvant in immune responses against Leishmania major induced by thiol-specific antioxidant-based protein vaccine. J. Parasit. Dis. 40, $760-767$ (2016).

24. Messias, J. B. et al. Avaliação dos parâmetros hematológicos e bioquímicos de ratas no segundo terço da gestação submetidas à ação do extrato metanólico de Cereus jamacaru D C., Cactacea. Rev. Bras. Farmacogn. 20, 478-483 (2010).

25. Marques, P. E. et al. Chemokines and mitochondrial products activate neutrophils to amplify organ injury during mouse acute liver failure. Hepatology. 56, 1971-1982 (2012).

26. Cangussu, A. S. R. et al. A hybrid protein containing MSP1a repeats and Omp7, Omp8 and Omp9 epitopes protect immunized BALB/c mice against anaplasmosis. Vet. Res. 49,6 (2018).

27. Brandi, I. V. et al. Total combining power: Technique for the evaluation of the quality control process of clostridiosis vaccines. $J$ Microbiol Methods. 130, 164-168 (2016).

28. Reed, L. J. \& Muench, H. A simple method of estimating fifty percent end points. Am. J. Epidemiol. 27, 493-497 (1938).

29. Cai, D. et al. Enhanced immune responses to E2 protein and DNA formulated with ISA 61 VG administered as a DNA primeprotein boost regimen against bovine viral diarrhea vírus. Vaccine. 36, 5591-5599 (2018).

\section{Acknowledgements}

We acknowledge Prof. Dr. Carla Verônica Rodarte de Moura - Department of Chemistry, Center for Natural Sciences - CCN, Federal University of Piauí - UFPI, Teresina-PI, Brazil for assistance and use of the Malvern instruments Zetasizer Nano ZS90; Prof. Dr. Lucas Samuel Soares for W/O 40/60 nano-emulsion analysis. We acknowledge also Prof. Dr. Berghmann M Ribeiro - University of Brasília, Institute of Biological Sciences, Department of Cell Biology for his availability and training of the graduate students in the immunoblotting techniques. We acknowledge the UFT Biotechnology Graduate Program for their collaboration and support for the graduate studies of Mellanie Karoline do Carmo Felix and also CNPq project number 315095/2018-0. 


\section{Author Contributions}

M.K.C.F., T.T.D. and A.S.R.C. - performed the experiments for immunization of swiss mice. I.V.B., E.M.S., K.S.C., K.F.V. - Analysis of alpha toxin production. L.S.S.S., A.S.R.C., R.W.S.A. - analysis of the nano-emulsion. M.K.C.F., R.F.T.C. and B.M.R. - immunoblotting techniques analysis. L.A.M., P.A.N. and B.M.R. revision of the manuscript for English language and technical aspects of the work.

\section{Additional Information}

Competing Interests: The authors declare no competing interests.

Publisher's note Springer Nature remains neutral with regard to jurisdictional claims in published maps and institutional affiliations.

(c) (i) Open Access This article is licensed under a Creative Commons Attribution 4.0 International License, which permits use, sharing, adaptation, distribution and reproduction in any medium or format, as long as you give appropriate credit to the original author(s) and the source, provide a link to the Creative Commons license, and indicate if changes were made. The images or other third party material in this article are included in the article's Creative Commons license, unless indicated otherwise in a credit line to the material. If material is not included in the article's Creative Commons license and your intended use is not permitted by statutory regulation or exceeds the permitted use, you will need to obtain permission directly from the copyright holder. To view a copy of this license, visit http://creativecommons.org/licenses/by/4.0/.

(C) The Author(s) 2019 